\title{
Significados das emoções no futebol brasileiro e argentino: um diálogo em contextos etnográficos distintos
}

\author{
Meanings of emotions on Brazilian and Argentinean football: \\ a dialog in distinct ethnographic contexts
}

\author{
Gustavo Andrada Bandeira \\ Universidade Federal do Rio Grande do Sul (UFRGS), Porto Alegre / Brasil \\ Doutorando em Educação, UFGRS \\ gustavo.bandeira@ufrgs.br \\ Maria Nemesia Hijós \\ Universidad de Buenos Aires (UBA), Buenos Aires / Argentina \\ Doutoranda em Ciências Sociais, UBA
}

\begin{abstract}
RESUMO: Neste trabalho, pretendemos destacar como as emoções são narradas e representadas em dois contextos etnográficos distintos. No primeiro contexto etnográfico se procurou observar um currículo de masculinidade nos estádios de futebol em Porto Alegre, Brasil. Nosso segundo contexto é uma investigação acerca dos processos de 'modernização' da gestão esportiva em um clube de futebol, em Buenos Aires, na Argentina. Nos propomos a interpretar de que modo emoções e sentimentos são entendidos para a construção de masculinidades ou para as narrativas comercias do 'produto futebol'. Se, em alguma medida, o amor e as emoções permitiriam questionar os ditos hegemônicos da cultura ao tensionar as permissividades de performatividades de gênero ou de uma lógica cartesiana de causa e efeito ou da necessidade produtiva, elas também podem enquadrar os sujeitos repetindo disputas de gênero e de consumo. Essa experiência afetiva não é nem uma contestação absoluta às normas vigentes nem uma aceitação total das mesmas. Ela seria mais bem entendida como um campo de possibilidades de vivências, de pertencimento e construção de subjetividade. Talvez os afetos estejam em disputa e nos parece que lutar por essa causa seja bastante justo.
\end{abstract}

PALAVRAS-CHAVE: Emoções; Masculinidade; Consumo; Futebol.

ABSTRACT: On this paper, it is intended to highlight how emotions are narrated and represented in two specific ethnographic contexts. In the first ethnographic context, a curriculum of masculinity in football stadiums in Porto Alegre, Brazil, was observed. Our second context is an investigation about the processes of 'modernization' of sportive management in one football club, in Buenos Aires, Argentina. We purpose to interpret how emotions and feelings are understood for the construction of masculinities or for the commercial narratives of the 'football product'. If, in anyway, love and emotions would permit questioning the hegemonic sayings of the culture when the permissiveness of gender performativities were tensioned or when a Cartesian logic of cause and effect or when a productive necessity were tensioned as well, they also can produce a framework of the individuals repeating gender and consume disputes. This affective experience is neither an absolute contestation to the current norms nor a total acceptation of them. It could be better understood as a field of possibilities of experiences, as well as of a feeling of belonging and construction of subjectivity. Maybe the affections are in dispute and it seems to us that fighting for this cause is quite fair.

KEYWORDS: Emotions; Masculinity; Consume; Football. 
Entendemos o futebol como um artefato cultural que ensina comportamentos, valores, modos de ser e estar no mundo. Nessa perspectiva, o futebol é entendido como produtor de marcas culturais e não um mero reprodutor das mesmas. Nesse trabalho, pretendemos destacar como as emoções são narradas e representadas em dois contextos etnográficos distintos. Propomo-nos a interpretar de que modo emoções e sentimentos são entendidos para a construção de masculinidades ou para as narrativas comercias do 'produto futebol'.

O primeiro contexto etnográfico é o material empírico de uma dissertação de mestrado em educação em que se procurou observar um currículo de masculinidade nos estádios de futebol em Porto Alegre, Brasil. ${ }^{1}$ Para o que nos propomos aqui, os cânticos ditos coletivamente no estádio ganharão maior relevo. Tentaremos descrever de que forma os torcedores cantaram seus pertencimentos e como as emoções produziram uma vinculação desses torcedores com seus clubes e que lugar ocuparam nesse currículo de masculinidade.

Nosso segundo contexto é uma investigação acerca dos processos de 'modernização' da gestão esportiva em um clube de futebol, em Buenos Aires, na Argentina, produzidos para um trabalho de conclusão do curso de graduação em ciências antropológicas. ${ }^{2}$ Tentaremos problematizar como a gramática empresarial dialoga e/ou é resistida por conceitos utilizados por antigos sócios e dirigentes substituídos, especialmente a partir dos anos de 1990, por atores mais vinculados ao campo da administração profissional e do marketing.

Em diferentes esferas da cultura, as emoções são narradas como condição de humanidade. Quem não possui determinados sentimentos, considerados adequados frente a um determinado fenômeno, poderá ser adjetivado, em casos mais graves, de monstruoso. Ao mesmo tempo, o controle das emoções é recheado de valores positivos dentro de diferentes modalidades discursivas, desde o cristão que não se deixa cair em tentação até o centroavante que não teme o estádio cheio na hora da conclusão a gol.

\footnotetext{
${ }^{1}$ BANDEIRA. "Eu canto, bebo e brigo... alegria do meu coração".

${ }^{2}$ HIJÓS. El deporte como mercancía.
} 
Não entendemos as emoções apenas como estados subjetivos e privados, mas como práticas discursivas envolvidas em relações de poder. 0 entendimento de que as emoções não são naturais ou inatas não visa diminuir o envolvimento dos indivíduos ou mesmo as sensações viscerais como os choros, enjoos ou as tonturas de uma partida de futebol, mas pretende colocá-las dentro do circuito da cultura verificando como diferentes discursos se articulam, se complementam ou se rechaçam neste contexto.

\section{MODOS DE OBSERVAÇÃO NOS DIFERENTES CAMPOS EMPÍRICOS}

Acreditamos que, por honestidade ao leitor, precisamos marcar desde o início o pertencimento dos pesquisadores. A interpretação dos fenômenos nunca é neutra e por esse motivo o lugar de onde os pesquisadores falam é muito importante para apontar em uma direção ou em outra. Antes de seguirmos com a explanação, entendemos ser necessário marcar nossa vinculação com as torcidas de futebol. Somos torcedores de futebol vinculados aos clubes em que realizamos as investigações. No caso do trabalho com as torcidas em Porto Alegre, o investigador é gremista, enquanto na investigação com os dirigentes do Boca Juniors, a pesquisadora é torcedora do azul $y$ oro. Ao fazer essa explicitação reforçamos nosso envolvimento com o tema e acabamos deixando bastante evidentes alguns dos atravessamentos que nos possibilitam questionar nossas próprias interpretações.

Na perspectiva dos estudos culturais, a linguagem possui preponderância. Ela não apenas descreve os acontecimentos, ela os produz. Essa produção, no caso do futebol acontece em diferentes âmbitos. Ao realizar a expressão pública dos sentimentos, os torcedores colocam em jogo o que é desejado de ser sentido ou o que pode ser entendido como emocionante nos estádios de futebol, além de marcar qual o lugar que as emoções ocupam e que práticas elas legitimam ou não. Ao mesmo tempo em que definem a paixão dos torcedores como um produto a ser comercializado, os dirigentes constroem esse produto e dão a ele determinado valor de mercadoria que poderá ser convertido em valor pecuniário.

No trabalho realizado nos estádios, foi realizada uma etnografia pós-moderna, da forma como ela vem sendo utilizada em algumas pesquisas em educação, com observações participantes e a construção de diários de campo. Para a construção do 
material empírico, foram frequentados os estádios José Pinheiro Borda, Beira-Rio, do Internacional, ${ }^{3}$ e Olímpico Monumental, Olímpico, do Grêmio. Foi assumida, para além das transcrições e relações, um esforço em descrever os acontecimentos nos diários de campo. ${ }^{4}$

O contexto de observação produz boa parte da experiência que se tornará inteligível. As torcidas da dupla Gre- $\mathrm{Nal}^{5}$ foram observadas nos dias de jogos e dentro dos seus estádios. Christian Bromberger salienta que durante as partidas (ou outros eventos esportivos) aparecem "as dimensões salientes da experiência social e cultural (a relação com o corpo, a afirmação das identidades, o lugar da competição nas sociedades contemporâneas, as novas formas de heroísmo...)”. ${ }^{6}$ Entendemos os estádios de futebol como instituições que possibilitam determinadas práticas e inibem outras. Procuramos visualizar nesse contexto as ações que produzem determinadas representações de masculinidades por esses sujeitos coletivos: 'torcida do Grêmio'7 e 'torcida do Internacional'.

Os jogos observados foram os da primeira fase do Campeonato Gaúcho. Como observa Arlei Damo, “é preciso estar atento, pois apenas alguns jogos são 'absorventes'. Outros são 'desinteressantes' e há também os 'meia-boca', como dizem os torcedores". 8 A escolha pelos jogos "meia-boca" foi teórica e política. Entendemos que esses "jogos comuns' permitiriam enxergar o que se poderia chamar de 'cotidiano' dos estádios de futebol. Mesmo que os eventos em estádios do football association sejam sempre eventos extraordinários na vida diária dos torcedores e mesmo das cidades, alguns eventos poderão ser mais ou menos comuns. Jogos com menor público ou que o resultado seja mais previsível ajudam a visualizar quais as narrativas são produzidas e qual o comportamento da torcida nessas partidas 'menores'. Buscamos com essa escolha indagar o que acontece nos jogos comuns, nas vitórias, jogos narrados pelo viés de apenas um clube. Jogos em que o adversário, supostamente, importa menos. Procuramos pensar que emoções circulam e são narradas nos estádios em momentos de 'menos emoção'.

\footnotetext{
${ }^{3}$ Para dar fluidez ao texto optamos por utilizar os "nomes fantasia" dos clubes da forma como esses são referidos na imprensa esportiva e por grande parte de seus torcedores.

${ }^{4}$ GEERTZ. A interpretação das culturas.

${ }^{5}$ Gre-Nal é o termo utilizado para as partidas entre Grêmio e Internacional, além de ser utilizado, quando antecipado do termo dupla, para referir-se aos dois clubes.

${ }^{6}$ BROMBERGER. As práticas e os espetáculos esportivos na perspectiva da etnologia, p. 241.

${ }^{7}$ Utilizamos aspas simples no texto quando procuramos fazer algum destaque ou utilizar as palavras com outros sentidos que não os convencionais; o uso de aspas duplas aparecem quando utilizamos citações, palavras e/ou expressões de outros autores.

${ }^{8}$ DAMO. Do dom à profissão, p. 404.
} 
Para não ficar apenas com as observações de campo sobre as manifestações dos torcedores, pareceu-nos produtivo, também, observar jornais da cidade de Porto Alegre, nos dias de jogos e posteriores, com objetivo de observar como os especialistas 'prepararam' o ambiente do estádio de futebol e depois como interpretaram os fenômenos que lá ocorreram. A seleção desses diferentes materiais, as manifestações das torcidas nos estádios e os textos veiculados em jornais, pretendeu representar diferentes vozes desse contexto. A ideia foi partir desses diferentes olhares para produzir outro olhar sobre as representações de emoções que ali aparecem.

Na Argentina, o Boca Juniors promoveu uma transformação em sua gestão de futebol, adjetivado de moderno, através da participação de líderes com um perfil mais voltado para os negócios. Essa transformação foi mais evidente durante a presidência de Mauricio Macri, entre os anos de 1995 e 2007. Seu estilo e forma de conduzir a instituição promoveram a 'modernização' do clube em vários aspectos, diferindo da organização tradicional, tentando fortalecer sua imagem como clubes de outros esportes.

O objetivo desta investigação foi verificar de que forma se desenvolveu esse processo de transformação que cruzou o clube, bem como outras organizações esportivas na Argentina, a partir da reforma estrutural da década de 1990, encorajado pela implementação de políticas neoliberais. Também foi interessante investigar como o modelo de modernização, que surgiu na Europa tentando transformar o futebol em uma plataforma de negócios e comunicação para o público acabou, por vezes, relegando, inclusive, a importância do evento esportivo em si. Buscamos avaliar os discursos e representações dos torcedores, a fim de observar como eles entenderam as técnicas e estratégias implementadas pela direção do clube a fim de modernizar a instituição.

O trabalho de campo envolveu uma integração gradual, com diferentes níveis de observação e participação em vários quadros de interação com diferentes atores. As entrevistas foram realizadas para conhecer os significados de práticas, discursos e representações de dirigentes, funcionários, parceiros e torcedores sobre as mudanças que foram estabelecidas no clube a partir dos anos de 1990. A unidade de análise foi representada por um conjunto de práticas e representações de torcedores e parceiros atuais, além de líderes de gestões anteriores, gerentes e ex-gerentes de vários departamentos, consultores de marketing e empregados do clube, em contextos diferentes e em diversas situações sociais. 0 estádio e as suas instalações formaram a 
unidade de estudo e de trabalho de campo levando em consideração a rede de conexões e espaços que os atores estavam criando.

Durante a primeira fase do trabalho de campo, a expectativa era de que seria impossível encontrar um torcedor do Boca Juniors que poderia enunciar quaisquer comentários negativos sobre a gestão de Mauricio Macri, uma vez que, ele conseguiu colocar reconhecimento esportivo e exibição internacional através de vários títulos e jogadores importantes. Era, portanto, necessário ficar longe dos líderes que tinham acompanhado Macri durante os anos de 1990 e frequentar outros espaços e ouvir outras pessoas para além dos trabalhadores.

Entre esses novos espaços, visitamos um clube localizado a poucos quarteirões do estádio La Bombonera para ouvir os torcedores. Esse pequeno clube era frequentado por um grupo que variava entre seis ou sete torcedores entre 27 e 35 anos, de diferentes bairros e cidades da Província de Buenos Aires. Todos eles eram sócios e fiéis seguidores do Boca Juniors. Eles frequentavam a arquibancada popular em que se localiza a torcida organizada La 12. Este grupo reunia-se religiosamente antes de cada partida neste clube para compartilhar o almoço, lanche ou jantar (não importando o tempo, eles comiam churrasquinhos, choripans ou empanadas fritas, acompanhadas por cervejas litro). Em encontros casuais com esses torcedores, eles expressavam a pouca inclusão desenvolvida na gestão macrista, observando que a maioria das reformas e revisões feitas pelos parceiros, considerava um único setor da torcida e dos sócios: a "nobreza". Em suas conversas surgiram comentários políticos díspares, mas todos concordavam que as medidas de 'modernização' beneficiariam poucos torcedores e que, "se o Boca são as pessoas, não podem elitizar La Bombonera".9 Vários deles faziam reivindicações perante a dificuldade de conseguir ingressos para não-sócios: "não queremos um estádioshopping com todos os assentos, queremos ir para La Bombonera", conforme diziam.

\section{EM NOSSO MEIO DE CAMPO AS REPRESENTAÇõES DAS EMOÇÕES}

Dentro da análise culturalista, a representação possui uma esfera preponderante, ela é produtora de sentidos. A representação das emoções não é uma descrição sobre o que as emoções são ou deveriam ser. A representação opera, ela dá sentido. 0 que se diz sobre

\footnotetext{
${ }^{9}$ Optamos por utilizar o itálico para destacar esse material produzido no campo.
} 
as emoções é a forma de significação desses sentimentos. Interessa menos ou não interessa verificar a veracidade dessas construções, mas descrever de que forma aparecem em diferentes instâncias culturais, ditos sobre: o amor, a paixão ou o pertencimento.

Dessa maneira, a expressão oral de sentimentos nas diferentes culturas não pode ser pensada como fenômenos exclusivamente psicológicos ou fisiológicos. Elas são inseridas dentro de um contexto simbólico que em alguns casos não deixará muitas alternativas para quem quiser associar-se a determinado grupo identitário que não seja sentir uma grande angústia ou uma grande felicidade diante de situações específicas. Geralmente, nas manifestações coletivas, é possível visualizar as ideias e sensações de uma determinada coletividade. ${ }^{10}$

Na perspectiva da "antropologia das emoções", as emoções estão associadas a uma interpretação e avaliação de um determinado estímulo que possui seu sentido construído historicamente, permeado por relações de poder. Como qualquer outro fenômeno cultural, as emoções são construções sociais, "não faz sentido [...] falar de emoções inatas e universais, idênticas através das culturas e através do tempo". ${ }^{11}$ Assim como as diferentes sociedades produzem entendimentos coletivos que organizam e orientam as vidas individuais dos sujeitos, “[...] ela também produz sentimentos coletivos, necessários para a manutenção do consenso social".12

Nessa perspectiva existe uma aprendizagem de esquemas ou padrões que acontecem em interação com o ambiente social e cultural. Aprende-se como, quando e por quem se pode manifestar determinados sentimentos. É necessário, também, a aquisição de um "conjunto de técnicas corporais que incluem expressões faciais, gestos e posturas". ${ }^{13}$ Marcel Mauss pensando na obrigatoriedade da manifestação de sentimentos justifica que as ações mais viscerais como lágrimas, gritos e lamentações não se resumem a sentimentos individuais, mas são pautados por uma gramática comum. Não sendo resumidas a ações espontâneas, as emoções são perpassadas por relações de poder e moralidades que demarcam fronteiras entre grupos sociais. ${ }^{14}$

A cultura contemporânea realiza importantes esforços na manutenção de certo padrão 'aceitável' de comportamento e de demonstração das emoções. Na vida cotidiana

\footnotetext{
${ }^{10}$ MAUSS. A expressão obrigatória dos sentimentos.

${ }^{11}$ PUSSETI. Emoções migrantes, p. 3.

12 REZENDE. Mágoas de amizade, p. 71.

${ }^{13}$ REZENDE; COELHO. Antropologia das emoções, p. 30.

14 REZENDE; COELHO. Antropologia das emoções, p. 30.
} 
somos incentivados a mantermos a calma e a controlar diferentes impulsos. Diferentes atividades de lazer têm recebido a responsabilidade de produzir momentos em que essas regras fiquem em suspensão. Desde os chamados esportes radicais passando por uma série de consumos excessivos, diferentes espaços - dentre eles os estádios de futebol - foram criados para atividades 'mais livres' (melhor entendidas como demarcadas por outros tipos de constrangimentos) em relação ao comportamento que serviriam, de alguma maneira, para ajustar a excitação reprimida em outros momentos cotidianos. As atividades recreativas poderiam permitir que os sujeitos tivessem uma maior excitação em que imitariam a 'vida real', mas sem os riscos envolvidos nessa mesma 'vida real'. As práticas torcedoras, em diferentes contextos, estão sempre investidas de uma grande carga de emoções. "Nenhuma outra forma de cultura popular engendra uma paixão ampla e participativa entre seus adeptos como a que se tem pelo futebol". ${ }^{15}$

Norbert Elias ressalta que a capacidade de controlar os impulsos não é inata aos seres humanos. ${ }^{16}$ Ele sugere, porém, que o autocontrole poderia ser entendido como um universal do humano, na medida em que todas as culturas constroem conteúdos de autocontrole a serem aprendidos por quem quiser o estatuto de humano em um contexto específico. Judith Butler afirma que os sentimentos estão em parte condicionados por nossas interpretações de mundo. Essa interpretação não é fixa e pode ser modificada fazendo como que se modifique também a forma como sentimos. "Nuestro afecto nunca es solamente nuestro: desde el principio, el afecto nos viene comunicado desde otra parte". ${ }^{17}$ Os sentimentos são sempre tributários do contexto cultural e de relações sociais em que aparecem. ${ }^{18}$

\section{O AMOR MASCULINO DOS TORCEDORES DE FUTEBOL NO ESTÁDIO}

Na representação das emoções dos torcedores de futebol nos estádios em Porto Alegre, o amor romântico ocupa um espaço preponderante. 0 encontro com o clube pode representar um 'encontro de almas' e pode ser entendido como a construção de um sujeito completo. Como qualquer marcador identitário essencializador, torcer por um

\footnotetext{
${ }^{15}$ GIULIANOTTI. Sociologia do futebol.

${ }^{16}$ ELIAS. Introdução.

${ }^{17}$ BUTLER. Marcos de guerra, p. 79.

${ }^{18}$ REZENDE; COELHO. Antropologia das emoções.
} 
clube de futebol faz o inconstante sujeito múltiplo virar, no caso desses estádios, colorado ou gremista. Uma faixa no estádio Olímpico era bastante ilustrativa da ideia de completude que essa associação provoca "sou gremista e me basta". O amor ao clube também realiza uma das principais plenitudes do amor, ele é da ordem do para sempre. Ele seria o espaço da realização da loucura do amor contemporâneo que seria "desejar um amor permanente, com toda a intensidade, sem nuvens ou tempestades". ${ }^{19}$

As relações dos torcedores com seu clube também obedecem a uma 'lógica' e a uma 'racionalidade' parecida com a dos amantes. Esse amor, como todo 'amor verdadeiro', precisa ser intenso. Os torcedores "sofrem emoções como quem sofre golpes. Passam por mil martírios" ${ }^{20} 0$ excesso de emoções também pode desqualificar o sujeito torcedor para explicar de forma adequada os fenômenos que acontecem durante as partidas, "afora os fanáticos (aqueles que enxergam tudo distorcidamente pela paixão), todos os demais colorados sabem que o time foi um desastre contra o Juventude e não cabe reclamar da arbitragem". ${ }^{21}$ Esse excesso e sofrimento não diminuem em nada essa relação ou a virtude do amor. No período do Romantismo "muitos começam a se convencer de que 'amar é sofrer' e quem não quiser sofrer deve desistir de amar",22 interpretação contemporaneamente recorrente. Por mais temerário, irracional ou doentio que seja o 'excesso amoroso', “quem participa do jogo amoroso aprendeu que o excesso emocional é imprescindível à ideia de felicidade ou de vida bem-sucedida". ${ }^{23}$

Naquilo que poderíamos chamar de 'nossa cultura', masculinidade e emoções não possuem grande proximidade. Em alguns casos seria justamente a frieza ou a falta de sentimentos ou de emoções que qualificaria, ao menos no senso comum, um homem 'verdadeiramente homem'. Existe um bom número de limitações para os sujeitos masculinos demonstrarem afetos publicamente. A amizade masculina, muito significativa em diferentes momentos históricos, perdeu seu status desde o período vitoriano. "Os sentimentos de camaradagem masculina foram em grande parte relegados a atividades marginais, como o esporte ou outras atividades de lazer, ou ainda a participação na guerra". ${ }^{24}$

\footnotetext{
${ }^{19}$ PRIORE. História do amor no Brasil, p. 321.

20 PRIORE. História do amor no Brasil, p. 12.

${ }^{21}$ DENARDIN. Sem choradeira, p. 14.

${ }^{22}$ COSTA. Sem fraude nem favor, p. 11-12.

${ }^{23}$ COSTA. Sem fraude nem favor, p. 195.

${ }^{24}$ GIDDENS. A transformação da intimidade, p. 55.
} 
Algumas narrativas sobre a participação dos torcedores nos estádios de futebol argumentam que nesses contextos barreiras sociais são reduzidas, diferenças suprimidas e as permissividades ampliadas; seria possível entender que a "efervescência coletiva corresponde [a] uma mudança de personalidade". ${ }^{25}$ Algumas descrições mais românticas falam em quebras de barreiras sociais e liberdade total de expressão. Na realidade, como em qualquer contexto de produção de identidades coletivas, as ordens sociais são reorganizadas.

A expressão de sentimentos possui um espaço privilegiado nos estádios de futebol. Os torcedores são inseridos em uma comunidade de sentimento que é aflorada pelas falas, odores e cores que produzem a reorganização das identidades e alteridades por aquilo que Arlei Damo define como clubismo, "um sistema de representação estruturado, de forma que o indivíduo, ao tornar-se torcedor, é capturado por códigos que orientam seu comportamento e moldam a sensibilidade". ${ }^{26}$ É possível inferir que a percepção ética, estética e moral é atravessada por essa comunidade de sentimento. Nos noventa minutos de uma partida de futebol é possível sentir as emoções de toda uma vida: felicidade, sofrimento, ódio, angústia, admiração e sentimento de injustiça, porém, "para sentir plenamente estas emociones, hace falta ser partidario, ser hincha, pasar del 'ellos' al 'nosotros". ${ }^{27} 0$ pertencimento clubístico também "articula um sistema que movimenta as emoções a partir da relação pendular entre identidades (nós) e alteridades (eles/outros) ".28

Nessa inserção clubística os sujeitos aprendem que emoções podem, devem ser demonstradas, narradas e cantadas. A favor de quem ou contra quem, expressões de amor ou de repúdio podem, devem acontecer. Nessa transição não apagamos nossos demais atravessamentos identitários. Esses atravessamentos, porém, ficam englobados pela lógica do clubismo. Ser torcedor de um clube, time x, y ou z, é a representação mais significativa quando os sujeitos atuam nas arquibancadas e cadeiras dos estádios de futebol. Com forte intensidade emocional, estar em um estádio de futebol é estar identificado com uma determinada torcida.

\footnotetext{
${ }^{25}$ SEGALEN. Ritos e rituais contemporâneos, p. 87.

${ }^{26}$ DAMO. O espetáculo das identidades e das alteridades, p. 39.

${ }^{27}$ BROMBERGER. Significaciones de la pasión popular por los clubes de fútbol, p. 21.

${ }^{28}$ DAMO. Futebol, engajamento e emoção, p. 1.
} 
Nos cânticos esse pertencimento aparece muito ligado a sentimentos: "Sou, eu sou do Inter/ Um sentimento/ Que não pode acabar". ${ }^{29}$ Esse pertencimento não provoca uma homogeneização do torcer. Poderão ser todos colorados ou gremistas, mas as formas de participação no estádio de futebol são bastante diversificadas. Esses cânticos, quase sempre acompanhados por instrumentos de percussão, são originados, em sua ampla maioria, nas torcidas Popular do Internacional e Geral do Grêmio que se localizavam atrás de um dos gols, do Beira-Rio e do Olímpico. Esses torcedores acompanhavam as partidas em pé, pulando e cantando ininterruptamente durante boa parte do confronto diminuindo sua intensidade apenas no intervalo dos mesmos. Esse tipo de comportamento não era acompanhado por outros torcedores, como, por exemplo, os das cadeiras, que nos dois estádios acompanhavam a maior parte das partidas sentados e fazendo intervenções pontuais de xingamentos ao árbitro, ao adversário e também aos jogadores e treinadores de suas equipes.

A participação dos torcedores da Geral ou da Popular assemelha-se a forma de comportamento das hinchadas argentinas, onde

\begin{abstract}
[...] la fidelidad al equipo sin importar la situación por la que este atraviese, el fervor probado a través de cantos y saltos, son los instrumentos identificatórios de los simpatizantes con la hinchada. Aquellos sujetos que quieran ser reconocidos como parte de la hinchada deben llevar a cabo estas formas de actuar que son comunes a todos los integrantes. ${ }^{30}$
\end{abstract}

"Eu sou do Grêmio, senhor (graças a Deus)/ Cantamos todos com alegria/ Mesmo não sendo campeão/ 0 sentimento não se termina".

Nos estádios de futebol, contexto de intensa homofobia e violência potencial,31 aparecem grandes manifestações públicas de sentimentos e de afetos masculinos. Formas de afeto ambíguas são, nesse contexto, permitidas. Dentro do ritual das torcidas, nessa masculinidade torcedora exercida dentro dos estádios aparece uma série de ações não comuns no âmbito de uma masculinidade viril e guerreira tradicional e também muito presente nas representações dos torcedores de futebol. Poetas e outros homens mais 'preocupados' com o amor possuiriam uma masculinidade sob suspeita dentro

\footnotetext{
${ }^{29}$ A forma gráfica como escrevemos as letras dos cânticos é igual à dos sites das torcidas Popular do Internacional (http://www.guardapopularcolorada.com/) e Geral do Grêmio (http://www.ducker.com.br).

${ }^{30}$ GARRIGA ZUCAL. "Soy macho porque me la aguanto", p. 41-42.

${ }^{31}$ BANDEIRA. "Eu canto, bebo e brigo... alegria do meu coração".
} 
desse entendimento de masculinidade tradicional. Os torcedores do Grêmio cantam e dançam a música "Pingos de amor", que diz assim:

A vida passa eu telefono e você já não me atende mais (Grêmio! Grêmio!)/ Será que já não temos tempo nem coragem de dialogar... (Grêmio! Grêmio!)/ Ainda ontem pela praia alguma coisa me lembrou você! (Grêmio! Grêmio!)/ E veio a noite namorados se beijando e eu estava só... (Grêmio! Grêmio!)/ Vamos ser, outra vez nós dois.../ Vai chover, pingos de amor!

Além disso, nos estádios de futebol, demonstrações de afetos entre homens parecem não causar o mesmo impacto que em outras esferas da cultura. Arlei Damo entende que isso ocorre pela transição dos torcedores, essa alteração de estado que ocorre durante as partidas, especialmente nos estádios,

[...] em nossa cultura, são raros os espaços públicos nos quais os homens se permitem demonstrações de afeto, sobretudo entre iguais. Sem a transição que ocorre a caminho do estádio, uma espécie de percurso liminar que determina a transição de indivíduo à pessoa, do cidadão com nome e endereço para o anônimo (ou parcialmente anônimo) colorado [ou gremista], a espetacularidade não se instaura. ${ }^{32}$

Nos estádios, apesar de que apenas os jogadores joguem o jogo dentro das quatro linhas em dois tempos de quarenta e cinco minutos cada, os torcedores atuam em sua própria disputa. Das arquibancadas e cadeiras podemos ouvir os valores constantemente disputados. Em disputa podem aparecer jogos de classe dos torcedores 'empregadores' contra os atletas 'funcionários', jogos de gênero para saber que torcida é mais masculina que a outra e também jogos de afetividade. Mesmo que a afetividade e as narrativas amorosas ocupem um lugar de menor destaque nas construções de masculinidades nos estádios de futebol, quando a 'nossa torcida' ama deve amar mais e melhor que a torcida adversária.

Nessa produção de representações da relação entre os torcedores e seus clubes, o amor aparece como um elemento agregador, positivo. A ampla maioria das representações amorosas acrescenta adjetivos distintivos aos amores. 0 amor hierarquicamente superior é o que se poderia entender como o 'amor verdadeiro'. Nos estádios também conseguimos visualizar o 'bom amor'. Somente a nossa torcida conhece o 'verdadeiro amor'. 0 adversário não sabe amar. 0 amor de um gremista ou de um colorado, supostamente, jamais será entendido ou 'sentido' do mesmo modo por outro torcedor, uma vez que a discursividade amorosa faz com que os sujeitos acreditem que

\footnotetext{
${ }^{32}$ DAMO. Do dom à profissão, p. 402.
} 
ninguém será capaz de amar como eles, como por exemplo, no cântico da torcida do Grêmio: "Olha a festa macaco/ Torcida é coração/ Quem não canta é amargo/ Nunca vai sair campeão/ Inter cagão".

No futebol o homem jura amor eterno ao seu clube. "Sou Colorado e nada muda este sentimento /Porque é nas más que eu demonstro que te amo igual". Esse amor obedece a algumas regras do amor romântico e não pode ter fim. Algumas canções das torcidas fazem "a vinculação do amor-paixão-sacrifício [...] associado a ideia de que o amor verdadeiro jamais acaba". ${ }^{33}$ Cantam assim: "Mesmo não sendo campeão/ 0 sentimento não se termina/ É tricolor, e dale tricolor"; "Colorado é coração. / Trago, amor e paixão. / Pra sempre Inter!"

A participação do torcedor nos estádios acontece pela junção de diferentes sujeitos em uma identidade, que nesse contexto é intensificada. Mesmo quando um torcedor evoca individualmente algum cântico ou mesmo um grito, essa manifestação será avaliada pelos demais torcedores. Para que o cântico se espalhe ou para que o torcedor não sofra nenhuma reprimenda pelo seu grito, este deverá enquadrar-se na lógica do que é permitido ou não de ser dito naquele contexto.

\section{UMA MUDANÇA DE GESTÃo E A MERCANTILIZAÇÃO DAS EMOÇõES}

Um grande número de clubes argentinos, incluindo os que se tornaram grandes clubes de futebol ao longo do século XX nasceram como clubes de bairro. Esses clubes de bairro surgiram para cobrir os insuficientes investimentos estatais na construção de espaços de sociabilidade, culturais e esportivos tentando defender os direitos e assegurar o bemestar dos indivíduos, ajudando-os em seu desenvolvimento pessoal e oferecendo serviços que acompanhavam sua identidade. ${ }^{34}$ Essa tradição de práticas e essa mentalidade associativa já eram fomentadas desde a origem das sociedades civis e começou a cristalizar-se na década de 1930 seguindo o modelo de funcionamento das sociedades de fomentos dos bairros, bibliotecas populares, sindicatos e corporações empresariais. Nesses lugares se exerciam atividades cívicas, treinamentos da vida social e democrática.

\footnotetext{
${ }^{33}$ FELIPE. Do amor (ou de como galmourizar a vida), p. 33.

${ }^{34}$ FRYDENBERG. La crisis de la tradición y el modelo asociacionista en los clubes de fútbol argentinos.
} 
No início do século XX, quando a prática do futebol começou a se estender para jovens dos setores populares, o movimento de fundação de equipes - que eram, ao mesmo tempo, clubes esportivos - começou a se abrir cada vez mais à comunidade, dependendo da quantidade de sócios inscritos para seu crescimento. Assim como sustenta Julio Frydeberg, a partir desse laço cada vez mais forte com a comunidade, estes jovens deixariam de estar associados ao modelo original inglês para começar a marcar um estilo próprio de jogo mais relacionado com seu próprio contexto social, envolvendo outros valores como a beleza, a virilidade, a coragem e, fundamentalmente, a honra, dando forma a um estilo de cultura geracional. Os clubes que se formaram com um marcador identitário local acabaram permitindo a contestação de um modelo britânico mais tradicional. Essa formação no bairro acabava produzindo um tipo de vínculo e pertencimento que dava a ideia de que o clube era do bairro, do local ou, mais precisamente, de seus sócios.

Não ignorando as relações mercadológicas que sempre existiram no futebol, ao menos desde o início de sua era profissional, o novo marco político-econômico argentino e global dos anos de 1990 sentou as bases que permitiram um processo acelerado de 'modernização' no esporte. Nesta década, existiu uma dinâmica que legitimou a aplicação de recursos vigentes, atuais e inovadores na comercialização do futebol. Este uso de técnicas e estratégias no âmbito futebolístico poderia ser chamado de mercantilização, no sentido da implementação ordenada, acelerada e sistemática de medidas próprias do mercado contemporâneo. Este processo marca um antes e um depois, determinado por uma crescente ânsia em ganhar dinheiro, sob o paradigma de novas e distintas regras que vão reger o esporte, acompanhada de medidas para deixar os clubes mais 'ágeis'. Nesta mesma linha, a noção de 'moderno' se refere aqueles clubes esportivos que se organizam institucionalmente conforme os padrões europeus, desenvolvendo uma gestão empresarial e mercantil em torno dos produtos que transferem os valores da instituição aos atributos de uma marca. ${ }^{35}$

Na década de 1990, os clubes esportivos, antes dirigidos por seus sócios sem o necessário preparo profissional, substituem os seus comandos. Neste momento aparece a figura do manager, sujeito que deveria, partindo dos conceitos do mercado, angariar a

35 Cf.: CRUZ. A nova economia do futebol; GIL, Monopolio televisivo y "gerenciamiento"; GIULIANOTTI. Sociologia do futebol; TOLEDO. Torcedores e o mercado de bens futebolísticos; PRONI; ZAIA, Gestão empresarial do futebol num mundo globalizado. 
maior quantidade de recursos aos seus clubes. No Boca Juniors, esse processo teve início durante a gestão do atual presidente da república Argentina, Mauricio Macri. ${ }^{36}$ Após conseguir o financiamento necessário, os managers começaram a colocar esse dinheiro em tudo o que fosse vinculado a sustentar a visão e a missão do clube, desde o ponto de vista esportivo-empresarial. No caso da Argentina, para dar suporte a esses investimentos, foram introduzidas reformas nos estatutos de clubes. Neste contexto, os novos líderes aparecem como uma classe diferencial profissionalizada. Segundo Frederic nesse período é apresentada uma relação direta entre moral e política. ${ }^{37}$ Enquanto em anos anteriores, nos clubes esportivos, os valores comuns apareciam em relacionamentos horizontais formando uma comunidade moral que incluía valores como reciprocidade e lealdade locais, a partir dos anos de 1990 (com o avanço do modelo neoliberal), a atmosfera começou a ser animada por uma lógica legalista e que valorizava a hierarquia dos sistemas políticos, entendido como um ambiente de pouca moralidade. Esse descrédito se dá pela leitura de que as relações políticas são consideradas como indecentes e desonestas, suas práticas são corruptas ou clientelistas. No caso de Mauricio Macri, e dos novos atores que rodeavam o Boca Juniors (profissionais e especialistas), seu reconhecimento no mundo dos negócios, honra e reputação social permite supor que poderia significar um caso de assimetria e distância em relação aos outros clubes. No livro Pasión y gestión, Mauricio Macri argumenta que a visão que uniria toda a instituição seria "fazer felizes os torcedores do Boca", ao mesmo tempo em que a missão seria "recuperar a glória perdida". ${ }^{38}$ Ou seja, a visão do clube estaria voltada as emoções de seus torcedores.

\footnotetext{
${ }^{36}$ Mauricio Macri ao assumir a presidência do Boca Juniors formalizou o início de uma nova etapa na instituição. Mauricio Macri é filho de Alicia Blanco Villegas e Franco Macri, dono de um dos grupos econômicos mais importantes da Argentina. $\mathrm{O}$ grupo tem desenvolvido atividades relacionadas à construção imobiliária, indústria automobilística, coleta de lixo, indústria alimentar, mineração, correios, transportes, comunicações e concessões estaduais. Ele possui empresas na Argentina, Brasil e Uruguai, e está intimamente relacionado com o Grupo Socma (Sociedad Macri). Antes de entrar para este negócio, Macri estudou no prestigiado Newman College. Formou-se engenheiro civil pela Universidade Católica Argentina e fez vários cursos de pós-graduação na Argentina e nos Estados Unidos. Sua experiência de trabalho começou em uma das empresas familiares. Em 1984 se juntou Socma, e a partir de 1985 atuou como seu gerente geral. Em 1992 ocupou a vice-presidência em Sevel, empresa do ramo automobilístico do grupo econômico da família, assumindo a presidência em 1994. Um recurso que foi usado por ele para legitimar e construir a confiança como um líder de esportes foi, precisamente, seu capital, econômico e social. Macri foi presidente do Boca Juniors durante o período compreendido entre 1995 e 2007.

${ }^{37}$ FREDERIC. Buenos vecinos, malos políticos.

${ }^{38}$ MACRI; BALLVÉ; IBARRA. Pasión y gestión, p. 35-36.
} 
A situação econômica dos anos 1990 era favorável para Macri por pertencer ao mundo empresarial, devido à paridade existente entre o peso argentino e o dólar americano, o que lhe assegurava uma faixa de lucro maior que em outros períodos. Para ele, a intervenção do management desembocaria inerentemente no melhoramento das capacidades competitivas da equipe e permitiria gerar uma nova ordem na instituição esportiva. Estas intenções foram expressas nos discursos de sua campanha presidencial, em que se insistia na busca do equilíbrio correto entre a paixão (associada aos sentimentos) e a gestão (ligada à razão e à inteligência). 0 uso racional dos recursos disponíveis estimulados pela necessária paixão - conduziria ao êxito de uma empresa esportiva.

\section{A PAIXÃO E/OU O CONSUMO DOS TORCEDORES}

No contexto de uma mercantilização esportiva, os dirigentes dos clubes de futebol têm procurado transformar os torcedores fanáticos em consumidores fiéis. ${ }^{39}$ Quando os êxitos e as vitórias esportivas acompanham um determinado clube, não seria muito difícil de implementar essa lógica consumidora, uma vez que os torcedores seguiriam pagando e querendo consumir tudo o que exiba a marca do clube e seu vínculo a ela. Entretanto, um inconveniente poderia se apresentar quando essas vitórias esportivas não chegassem e a multidão de torcedores não estivesse de acordo com o rendimento do plantel. Esta seria a simplificação de uma perspectiva mais 'marqueteira'. É possível que uma equipe tenha um mau rendimento futebolístico e existam mais sócios e mais vendas, já que desde a gestão do clube se tenta reforçar os laços identitários para gerar apoio diante de situações esportivas adversas. Esses laços de pertença desvinculados dos resultados de campo também aparecem nos cânticos das torcidas. As emoções são convocadas para a manutenção do vínculo do torcedor com seu clube. Ao mesmo tempo esse vínculo é alvo de um sem número de oferta de produtos a serem consumidos.

Os torcedores 'tradicionais' (ou contrários ao processo de modernização) manteriam relações afetivas com os diferentes elementos de seu clube, os quais representam símbolos sagrados para eles: o estádio, a camiseta, os campeonatos, os troféus, mesmo que essa relação não estivesse pautada no consumo. Além disso esses torcedores, assumem um contrato cultural com a instituição, onde existe uma premência

\footnotetext{
${ }^{39}$ GIULIANOTTI. Sociologia do futebol.
} 
dos sentimentos e uma solidariedade local forte. Se bem que não possam ser considerados torcedores consumidores através da categoria utilizada por Giulianotti, ${ }^{40}$ também consomem alguns bens e produtos que são oferecidos pelo clube e suas empresas aliadas.

Também se pode pensar esta situação desde o ponto de vista de Viviana Zelizer que oferece uma visão aguda e sensível sobre as dinâmicas que podem apresentar os 'mundos hostis' da economia e da intimidade em algumas oportunidades estreitamente unidos e em outras separados. ${ }^{41}$ Por um lado, tal como coloca a autora, os especialistas em leis e dinheiro têm produzido discursos (jurídicos e econômicos) sobre 'os maus' originados na mistura de afeto e racionalidade no funcionamento do mundo moderno. Apesar de que, no senso comum, seja possível entender os âmbitos do dinheiro e dos afetos como 'mundos hostis', a autora aponta que a intimidade e a economia são erroneamente considerados mundos autônomos e antagônicos, que deveriam manter-se separados para evitar sua corrupção mútua. Atualmente, os indivíduos vão negociando estes processos em que o dinheiro e as paixões podem andar de mãos dadas.

O componente econômico-financeiro carrega uma importante carga moral no contexto futebolístico.

En la cultura futbolística la aparición de componentes económicos es disruptiva. Se trata más que nada de una cultura basada en mitos románticos. Aquello del amor por la camiseta, por los colores, por el club, por el equipo, un amor solo igual al materno o al filial. ${ }^{42}$

Pablo Alabarces ilustra as passagens semânticas (e toda a carga simbólica que isso carrega) dos sujeitos de povo a cidadãos e, neste momento, para consumidores. Boa parte das associações negativas que se realizam com os consumidores se valem de uma percepção de que este seria um sujeito facilmente manipulável ou, no mínimo, limitado na sua criatividade e ignorado enquanto agente social. Novas perspectivas da “antropologia do consumo" discordam desse viés.

[...] as relações que fundamentam o consumo são bem mais complexas, e geralmente nos chamam a pensar sobre questões mais amplas, abordadas através das subjetividades dos sujeitos, dos processos criativos definidores de um "estar no mundo", do poder e agência que os sujeitos se autoatribuem ao estabelecerem relações de produção-circulação-consumo. ${ }^{43}$

\footnotetext{
${ }^{40}$ GIULIANOTTI. Sociologia do futebol.

41 ZELIZER. La negociación de la intimidad.

${ }^{42}$ ALABARCES. Crónicas del aguante, p. 66.

${ }^{43}$ RIAL; SILVA; SOUZA. Consumo e cultura material, p. 14-15.
} 
O consumidor também pode ser pensado como um sujeito que interage com um universo material sendo parte constitutiva e constituinte de seu processo de "reprodução social". O consumo pode ser mais produtivamente pensado como "um processo em que os agentes se engajam na apropriação de bens, serviços, performances, informação ou ambiência". ${ }^{4}$ Discutindo diferentes legislações dos torcedores no contexto brasileiro, incluindo a lei 10.671, o Estatuto de Defesa do Torcedor, muito criticado por sua aproximação com o Estatuto de Defesa do Consumidor, Luiz Henrique de Toledo lembra que "os direitos do consumidor são uma marca política de nossos tempos, sem dúvida, e trazem as operações simbólicas de uma sociedade em constante transformação". 45

Dentro da 'mercantilização' dos clubes de futebol o foco, então, está desviado para que as paixões e emoções se difundam para criar e manter consumidores de futebol mais regulares para seguir mantendo o espetáculo com uma lógica cada vez mais mercantilizada.

Os clubes esportivos argentinos foram desde suas origens associações jurídicas sem fins lucrativos, cuja finalidade era a de dispor um espaço de lazer para a prática de diferentes esportes, sendo um local de recreação e sociabilidade, entrelaçado pelo espírito competitivo. Este tipo de associação tinha uma característica importante: colocar o clube nas mãos dos sócios, tendo como principal ponto forte o fator social e emocional. Porém, com a profissionalização da prática futebolística argentina em 1931, a rentabilidade econômica deste esporte começou a perfilar-se como um dos objetivos principais. Hoje a intenção de gerar lucros através das entidades esportivas é um feito, já que todo o ambiente que rodeia o futebol potencializa a circulação de grandes somas de dinheiro e acesso ao poder institucionalizado.

\section{O AMOR COMO A INTELIGIBILIDADE DO TORCEDOR}

As emoções poderiam aparecem como uma possibilidade privilegiada de resistência contra masculinidades tradicionais nos estádios de futebol. Seria, porém, ingênuo acreditar que existe uma quebra das restrições quanto aos afetos entre homens nos estádios de futebol. Quando os torcedores se abraçam, não se abraçam sujeitos tão

\footnotetext{
${ }^{44}$ GOIDANICH; RIAL. Um lugar chamado supermercado, p. 178.

45 TOLEDO. Torcedores e o mercado de bens futebolísticos, p. 316.
} 
desconhecidos assim e a qualquer momento. 0 amor ao clube é cantado por quase todos no estádio (por uns com maior intensidade que outros), porém os toques parecem mais restritos. O abraço do gol não parece possível, por exemplo, entre um torcedor e os vendedores ambulantes dos estádios, além de estarem temporalmente restritos aos gols e as vitórias.

Ao mesmo tempo em que o amor e as emoções são um marcador a mais na construção de representações dos torcedores de futebol, elas também podem reforçar a competição masculina. 0 amor que resiste a algumas práticas machistas dos estádios de futebol também hierarquiza as masculinidades. Mesmo que o amor não seja o atravessamento mais significativo da masculinidade do torcedor de futebol, se for para amar a nossa torcida tem o dever de amar mais que a torcida adversária para ser melhor e mais masculina que ela, "Te amo Inter, não somos como os putos da série B".

O amor dos torcedores de futebol, especialmente dos torcedores de estádio, é um amor específico, um amor em atuação, um amor, cantado, narrado e sentido de forma coletiva. Os torcedores amam juntos, os torcedores amam com seus familiares, amam entre homens. Amam o clube, o time, os jogadores e a própria torcida. Amar ao clube é pertencer a uma comunidade afetiva, é demonstrar a eternidade do amor, é ser melhor torcedor por amar mais o seu clube que o torcedor adversário. Dentro da própria torcida, quanto mais apaixonado, o indivíduo poderá requerer a condição de mais torcedor.

Esse amor ou essa paixão produz vínculos dos torcedores com seus clubes esses vínculos poderão ser convocados durante as partidas, mas também na aquisição de produtos. 0 torcedor ama, canta, se emociona e compra. Nesse diálogo entre torcedor fanático e consumidor fiel borrados em um mesmo indivíduo, consumir pode se aproximar do pertencimento, poderá ser mais uma 'prova de amor'. Além da marca, pertencimento e, mesmo, felicidade podem ser convertidos em bens de consumo. 0 que parece gerar maior tensão é certo entendimento de que o consumo é a chave de inteligibilidade deste afeto. Neste caso, os torcedores 'tradicionais' colocam suas ressalvas tentando marcar seu espaço de vínculo afetivo com o clube.

A paixão e o fervor dos torcedores os afastam do que pode ser costumeiramente entendido como lógico e razoável. A paixão os descredencia a dar opiniões sobre as partidas assim como os fazem enfrentar preços abusivos na aquisição de bens de que não necessitam. Se, em alguma medida, o amor e as emoções permitiriam questionar os ditos hegemônicos da cultura ao tensionar as permissividades de performatividades de 
gênero ou de uma lógica cartesiana de causa e efeito ou da necessidade produtiva, elas também podem enquadrar os sujeitos repetindo disputas de gênero e de consumo. Essa experiência afetiva não é nem uma contestação absoluta às normas vigentes nem uma aceitação total das mesmas. Ela seria mais bem entendida como um campo de possibilidades de vivências, de pertencimento e construção de subjetividade. Talvez os afetos estejam em disputa e nos parece que lutar por essa causa seja bastante justo. 


\section{REFERÊNCIAS}

ALABARCES, Pablo. Crónicas del aguante: fútbol, violencia y política. Buenos Aires: Capital Intelectual, 2012.

BANDEIRA, Gustavo Andrada. "Eu canto, bebo e brigo... alegria do meu coração": currículo de masculinidades nos estádios de futebol. 2009. $128 \mathrm{f}$. Dissertação (Mestrado em Educação) - Programa de Pós-Graduação em Educação, Faculdade de Educação, UFRGS, Porto Alegre, 2009.

BROMBERGER, Christian. As práticas e os espetáculos esportivos na perspectiva da etnologia. Horizontes antropológicos: antropologia e esporte, Porto Alegre, ano 14, n. 30, p. 237-253, jul.-dez. 2008.

BROMBERGER, Christian. Significaciones de la pasión popular por los clubes de fútbol. Buenos Aires: Libros del Rojas, 2001.

BUTLER, Judith. Marcos de guerra: las vidas lloradas. Barcelona: Paidós, 2010.

COSTA, Jurandir Freire. Sem fraude nem favor: estudos sobre o amor romântico. Rio de Janeiro: Rocco, 1998.

CRUZ, Antonio Holzmeister Oswaldo. A nova economia do futebol: uma análise do processo de modernização de alguns estádios brasileiros. 2005. 123 f. Dissertação (Mestrado em Antropologia Social) - Programa de Pós-Graduação em Antropologia Social, Museu Nacional, UFRJ, Rio de Janeiro, 2005.

DAMO, Arlei Sander. O espetáculo das identidades e das alteridades: as lutas pelo reconhecimento no espectro do clubismo brasileiro. In: CAMPOS, Flavio de; ALFONSI, Daniela (org.). Futebol objeto das ciências humanas. São Paulo: Leya, 2014, p. 23-55.

DAMO, Arlei Sander. Futebol, engajamento e emoção. In: HELAL, Renato; AMARO, Fausto (org.). Esporte e mídia: novas perspectivas. A influência da obra de Hans Ulrich Gumbrecht. Rio de Janeiro: EdUERJ, 2014, p. 1 -28.

DAMO, Arlei Sander. Do dom à profissão: uma etnografia do futebol de espetáculo a partir da formação de jogadores no Brasil e na França. 2005. 435 f. Tese (Doutorado em Antropologia Social) - Instituto de Filosofia e Ciências Humanas, Programa de Pós-Graduação em Antropologia Social, UFRGS, Porto Alegre, 2005.

DENARDIN, Pedro Ernesto. Sem choradeira. Diário Gaúcho, Porto Alegre, 15-16 mar. 2008, p. 14.

ELIAS, Norbert. Introdução. In: ELIAS, Norbert; DUNNING, Eric. A busca da Excitação. Lisboa: Difel, 1992, p. 39-99.

FELIPE, Jane. Do amor (ou de como glamourizar a vida): apontamentos em torno de uma educação para a sexualidade. In: RIBEIRO, Paula Regina Costa et al. (org.). Corpo, gênero e sexualidade: discutindo práticas educativas. Rio Grande: Editora da FURG, 2007, p. 31-45.

FREDERIC, Sabina. Buenos vecinos, malos políticos: moralidad y política en el gran Buenos Aires. Buenos Aires: Prometeo Libros, 2004. 
FRYDENBERG, Julio. La crisis de la tradición y el modelo asociacionista en los clubes de fútbol argentinos. Algunas reflexiones. efdeportes.com, Buenos Aires: SEUBE/FFyL/UBA, ano 6, n. 29, jan. 2001.

GARRIGA ZUCAL, José. "Soy macho porque me la aguanto": etnografía de las prácticas violentas y la conformación de identidades de género masculino. In: ALABARCES, Pablo (org.). Hinchadas. Buenos Aires: Prometeo Libros, 2005, p. 39-58.

GEERTZ, Clifford. A interpretação das culturas. Rio de Janeiro: Guanabara Koogan, 1989.

GIDDENS, Anthony. O amor romântico e outras ligações. In: GIDDENS, Anthony. A transformação da intimidade. São Paulo: UNESP, 2003, p. 47-58.

GIL, Gastón. Monopolio televisivo y "gerenciamiento": el fútbol como mercancía. efdeportes.com, Buenos Aires: SEUBE/FFyL/UBA, ano 5, n. 26, out. 2000.

GIULIANOTTI, Richard. Sociologia do futebol: dimensões históricas e socioculturais do esporte das multidões. São Paulo: Nova Alexandria, 2010.

GOIDANICH, Maria Elisabeth; RIAL, Carmen. Um lugar chamado supermercado. In: RIAL, Carmen; SILVA, Sandra Rubia da; SOUZA, Angela Maria de (org.). Consumo e cultura material: perspectivas etnográficas. Florianópolis: Editora UFSC, 2012, p. 175-190.

HIJÓS, María Nemesia. El deporte como mercancía: un estudio sobre la dimensión económica y las múltiples lógicas en el Club Atlético Boca Juniors. 2013. Tesis (Licenciatura en Ciencias Antropológicas) - Facultad de Filosofía y Letras, Universidad de Buenos Aires, Buenos Aires, 2013.

MACRI, Mauricio; BALLVÉ, Alberto; IBARRA, Andrés. Pasión y gestión. Buenos Aires: Aguilar, 2009.

MAUSS, Marcel. A expressão obrigatória dos sentimentos. In: OLIVEIRA, Roberto Cardoso de (org.). Marcel Mauss. São Paulo: Ática, 1979, p. 147-153.

PRIORE, Mary Del. História do amor no Brasil. 2. ed. São Paulo: Contexto, 2006.

PRONI, Marcelo W.; ZAIA, Felipe. Gestão empresarial do futebol num mundo globalizado. In: RIBEIRO, Luiz Carlos (org.). Futebol e globalização. Jundiaí: Fontoura, 2007.

PRONI, Marcelo W. A metamorfose do futebol. Campinas: Unicamp; Instituto de Economia, 2000.

PUSSETI, Chiara. Emoções migrantes: afinidades e diferencias como factos políticos. In: Congresso da Associação Portuguesa de Antropologia, 3., Lisboa, 2006.

REZENDE, Claudia Barcellos; COELHO, Maria Claudia. Antropologia das emoções. Rio de Janeiro: Editora FGV, 2010.

REZENDE, Claudia Barcellos. Mágoas de amizade: um ensaio em antropologia das emoções. Mana, vol. 8, n. 2, p. 69-89, 2002.

RIAL, Carmen; SILVA, Sandra Rubia da; SOUZA, Angela Maria de. Consumo e cultura material: um campo de estudos em expansão (Prefácio). In: RIAL, Carmen; 
SILVA, Sandra Rubia da; SOUZA, Angela Maria de (org.). Consumo e cultura material: perspectivas etnográficas. Florianópolis: Editora da UFSC, 2012, p. 9-21.

SEGALEN, Martine. Ritos e rituais contemporâneos. Rio de Janeiro: FGV, 2002.

TOLEDO, Luiz Henrique de. Torcedores e o mercado de bens futebolísticos. In: CAMPOS, Flavio de; ALFONSI, Daniela (org.). Futebol objeto das ciências humanas. São Paulo: Leya, 2014, p. 307-319.

TOLEDO, Luiz Henrique de. Lógicas no futebol. São Paulo: Hucitec; Fapesp, 2002. ZELIZER, Viviana. La negociación de la intimidad. Buenos Aires: Fondo de la Cultura Económica, 2009. 